\title{
PRODUÇÃO E DISPONIBILIZAÇÃO DE ESTATÍSTICAS uma abordagem institucional
}

Sinésio Pires Ferreira

\begin{abstract}
Resumo: Os avanços tecnológicos, o aumento e a mudança do perfil da demanda por informações estatísticas e a produção de indicadores cada vez mais complexos têm obrigado a Fundação Seade, como as demais instituições produtoras de informações, a reciclar-se permanentemente.

Palavras-chave: informação estatística; produção de indicadores; banco de dados.

Abstract: Technological progress, the increase and changing profile of the demand of statistical information and the production of ever more complex indicators have required Fundação Seade, as well as other statisticproducing institutions, to constantly renew them selves in order to achieve their mission.

Key words: statistical information; production of indicators; database.
\end{abstract}

A importância da informação na sociedade contemporânea tem sido ressaltada por diversos autores que, de modo geral, associam-na aos progressos recentes nos campos das Tecnologias de Informação e Comunicação - TICs. Nesse contexto, a Fundação Seade e demais instituições de produção de informações estatísticas, pela própria natureza de suas atividades, estão sendo direta e indiretamente afetadas, mas com certas particularidades que este artigo busca salientar.

Entre os impactos que tais tecnologias causaram, destacam-se: aumento da velocidade de transmissão e de acesso às informações; aumento da capacidade de produzir, armazenar e transmitir informações; maior flexibilidade dos formatos em que as informações podem ser produzidas, armazenadas, disponibilizadas e acessadas; e crescimento da demanda por informações.

$\mathrm{O}$ último elemento apresenta características próprias, pois enquanto os demais derivam diretamente do desenvolvimento tecnológico, ele depende de como os usuários reagem às possibilidades abertas pelas TICs. Evidentemente, a maior demanda por informações decorre do interesse dos usuários e da qualidade das informações disponíveis, bem como das facilidades e do custo de acesso. Não há dúvidas de que governos, empresas, pesquisadores e diferentes segmentos sociais passaram a depender, crescentemente, do acesso às mais diversas fontes de informação para a realização de suas atividades, o que, por seu turno, tem provocado um novo impulso ao desenvolvimento e à difusão das TICs (Alberts et al., 2002).

Um dos elementos determinantes da crescente demanda por informações é o processo de globalização - em parte, ele próprio favorecido pela difusão das TICs -, caracterizado pela exacerbação da concorrência entre empresas que as faz buscar novos espaços para a valorização de seu capital, independentemente de sua localização geográfica, culminando, portanto, na busca permanente de informações. Contudo, tal como no âmbito global, é igualmente crescente a importância das informações no espaço local, uma vez que "se oferecem como uma âncora social a nos proteger da excessiva padronização cultural que nos vem no rastro da globalização" (Senra, 1999). Assim, na visão simplificada deste autor, "a informação resulta dever ser um bem público da maior relevância a atrair a atenção, seja dos atores e agentes voltados ao espaço global, mais afeitos aos problemas econômicos e financeiros, seja dos atores e agen- 
tes voltados ao espaço local, mais afeitos aos problemas sociais" (Senra, 1999).

Outro aspecto que merece menção, decorrente, em parte, da própria difusão das TICs, mas principalmente de avanços teóricos e metodológicos no campo da estatística e das ciências sociais aplicadas, refere-se a todo um conjunto de novos indicadores, de construção muito mais complexa que os tradicionais e que exigem, além de novas fontes de informação, equipamentos, softwares e conhecimentos técnicos avançados. Os indicadores sintéticos, as estatísticas espaciais e o georreferenciamento das informações estatísticas são exemplos desse movimento.

No caso brasileiro, um conjunto de fenômenos sociais, políticos e institucionais concorrem para a crescente demanda por informações, dando-lhe contornos próprios. Nesse contexto, podem-se mencionar a democratização do país, institucionalizada pela Constituição de 1988, uma série de novos preceitos constitucionais e legais que têm levado à descentralização da execução de políticas sociais, o crescimento dos controles das ações e dos gastos públicos, nas três esferas de governo, a expansão de políticas sociais focalizadas, de planejamento, execução e controle mais complexos, e a retomada do planejamento como instrumento para a intervenção pública, notadamente na esfera social.

Todos esses fenômenos implicam a necessidade de informações, em especial estatísticas, o que tem levado as instituições produtoras a se reaparelharem nos campos tecnológico, científico e administrativo, de modo que possam corresponder a tais demandas, num contexto de conhecidas restrições fiscais.

Na Fundação Seade, também, surgem esses desafios. O presente artigo não pretende abarcar todos os aspectos anteriormente mencionados, mas apenas destacar, numa abordagem histórica, como esses movimentos se sucederam, como as instituições produtoras de estatística, em particular a Fundação Seade, reagiram ou se anteciparam a eles e quais os desafios que ainda deverão ser enfrentados pelo Sistema Nacional de Estatística e pela Fundação, nesse caso, com destaque para seu sistema de armazenamento e disponibilização de dados.

\section{CRESCIMENTO E DIVERSIFICAÇÃO DA DEMANDA POR INFORMAÇÕES ESTATÍSTICAS}

Atualmente, as entidades produtoras de informação vêem-se alvo das mais distintas e crescentes demandas por informações. Isso as tem obrigado a se reorganizar com vista em atendê-las de modo adequado e permanente. São vários os elementos que explicam esse fenômeno, alguns de natureza "universal", como o progresso tecnológico e o processo de globalização, anteriormente mencionados, outros específicos ao Brasil, estreitamente relacionados com sua história recente. Diante das profundas mudanças por que nosso país tem passado, seria impossível, nesse espaço, tratar de todas elas e de seus impactos sobre a produção de estatísticas. Assim, destacaram-se algumas, talvez as mais visíveis, mas que, certamente, revelam apenas parte do problema.

A primeira foi o próprio processo de democratização. Decerto, é de se esperar que governos democráticos procurem desenhar suas políticas com base em informações estatísticas, uma vez que necessitam, permanentemente, prestar contas de suas ações à sociedade que os elegeu. Também tendem a ampliar os órgãos de controle e avaliação dessas ações, pois a transparência e a correção da ação governamental e do trato das finanças públicas estão entre os elementos centrais da democracia. Além disso, a agenda de atuação governamental deve ampliar-se, sobretudo, no campo social. Da mesma forma, novos personagens entram em cena, com os vários segmentos sociais $\mathrm{e}$ suas organizações, como sindicatos, partidos políticos e organizações não-governamentais, que também passam a utilizar, crescentemente, de informações estatísticas, seja para definir seus focos de atuação, seja para acompanhar a ação governamental.

Uma das conseqüências da redemocratização foi o processo de descentralização da ação pública, que se acentuou a partir dos anos 80 , como uma espécie de contraponto à grande centralização do poder político e da ação governamental do período autoritário. "Foi louvado como algo que, em si, resolveria todos os problemas intergovernamentais, sobretudo mediante a autonomia do poder local e, por conseguinte, o repasse das funções para Estados e municípios" (Abrucio; Soares, 2001). Uma das formas pela qual este processo se realizou, sobretudo ao longo da década de 90, foi a "municipalização" de várias tarefas públicas, vale dizer, o repasse de funções, pela União e pelos Estados, aos municípios, a quem delegam competências (Krell, 2003).

A maior proximidade entre os governantes e os cidadãos, que caracteriza a esfera municipal, é uma das principais justificativas da municipalização. Assim, esperase uma maior presença da sociedade na definição, no monitoramento e na avaliação das políticas públicas. De- 
certo, é necessário que os cidadãos disponham de instrumentos institucionais e de informações para que tais intenções se concretizem. Independentemente das avaliações que se possa fazer dos resultados desse processo, o fato é que surge a necessidade de se dispor de um grande conjunto de informações municipais e, em muitos casos, intramunicipais.

Contudo, como observou Krell (2003), uma das características da realidade administrativa brasileira é a superposição de tarefas de uma multiplicidade de órgãos públicos, agora distribuídos nas três esferas de governo. Ademais, este autor demonstra que ainda persistem grandes ambigüidades na distribuição de competências entre os entes federados. Se isso dificulta a fiscalização da atuação desses órgãos por parte da sociedade civil e dos organismos oficiais de controle, amplifica em muito a necessidade de informações para o planejamento, acompanhamento e avaliação das ações de governo, seja pelos próprios (e múltiplos) órgãos públicos responsáveis por essas ações, seja pelos diversos representantes da sociedade civil organizada.

Outra mudança, mais recente, da forma de atuação governamental, em especial no campo social, que tem implicado novas demandas por informações, foi a chamada focalização das políticas sociais. Várias das ações governamentais passaram a eleger segmentos específicos da população como seu público-alvo, requerendo para tanto informações detalhadas das características da população, de modo a permitir a identificação do segmento prioritário, objeto da intervenção, incluindo, em muitos casos, sua localização espacial e a construção de cadastros das famílias ou pessoas beneficiárias.

Poder-se-iam mencionar várias outras mudanças institucionais, sociais e econômicas que têm implicado aumento e diversificação das necessidades de informações, mas as mencionadas parecem suficientes para sugerir a extensão desse fenômeno. Um aspecto adicional, porém, merece ser destacado. Para que subsidiem a elaboração, o acompanhamento e a avaliação das ações governamentais, as informações estatísticas, além de cobrir amplo escopo temático e territorial, necessitam ser atualizadas permanentemente. Isso significa que não bastam informações censitárias, atualizadas a cada dez anos, nem as originárias de pesquisas amostrais, que são mais freqüentes, mas com possibilidades de desagregação espacial limitadas. Assim, as instituições produtoras de informações têm de valer-se ou de levantamentos primários específicos às necessidades de seus usuários - cujo custo, em geral, é muito elevado - ou da utilização de registros administrativos que, originalmente, foram construídos para outros fins. Expandem-se, assim, suas tarefas de permanente coleta, organização, avaliação, validação e disponibilização desses registros, ampliando significativamente o escopo de atuação dessas instituições.

\section{AVANÇOS METODOLÓGICOS}

A seção anterior procurou demonstrar que a demanda por informações estatísticas elevou-se expressivamente, nos últimos anos, e que suas características se alteraram: seu escopo temático passou a ser muito mais amplo e diversificado e seu detalhamento, no tempo e no espaço, bem maior.

Ao lado disso, uma série de avanços teóricos e metodológicos na produção de estatísticas e indicadores tornou muito mais complexa sua elaboração. Um dos mais conhecidos foi a busca por um substituto do PIB per capita como medida do desenvolvimento. Desde a década de 50 , há manifestações de insatisfação com este indicador. Em 1954, um relatório de especialistas da Organização das Nações Unidas (ONU, 1954) sugeria que a mensuração do bem-estar não deveria basear-se exclusivamente em indicadores monetários, mas em múltiplos componentes que, juntos, conformariam o nível de vida de um indivíduo ou uma população (Erikson, 1996). Desde então, diversos esforços têm sido realizados para atingir esse objetivo. A própria Fundação Seade, no final dos anos 80 , aportou sua contribuição por meio da Pesquisa de Condições de Vida - PCV, em que propõe um método de classificação das famílias em grupos com distintos graus de vulnerabilidade, seguindo uma abordagem multimensional, em substituição à tradicional adoção da linha de pobreza (Fundação Seade, 1992). ${ }^{1}$

No entanto, foi com o Índice de Desenvolvimento Humano - IDH, proposto pelo Programa das Nações Unidas para o Desenvolvimento - PNUD, que esta abordagem se generalizou. Inicialmente formulado para a comparação do desenvolvimento humano entre países, logo foi adaptado para medir a situação de municípios.

No Brasil, o escritório do PNUD patrocinou o Relatório Nacional de Desenvolvimento Humano, em 1996, e duas edições do Atlas de Desenvolvimento Humano, em 1998 e em 2003, respectivamente. Elaborado conjuntamente pelo Ipea, IBGE e Fundação João Pinheiro, o Atlas utiliza uma medida similar ao IDH - o IDH-M - e reconstituiu sua evolução para o período de 1970 a 1991, 
na primeira edição, e atualizou-o com as informações censitárias de 2000, na última. Desde sua divulgação, o IDH-M passou a ser utilizado, algumas vezes de forma imprópria, como referência para o planejamento e avaliação das políticas sociais no país.

A produção de um indicador composto, com a importância que o IDH passou a ter, levantou, entre os produtores e usuários de informações, uma série de questionamentos de ordem metodológica: por que excluir dimensões reconhecidamente importantes como as condições habitacionais e o meio ambiente? Que pesos atribuir às diversas dimensões consideradas? Que escalas adotar? Adicionalmente, à medida que passou a ser utilizado como instrumento para a definição e avaliação de políticas públicas, novos problemas se colocaram: o IDH seria suficiente para avaliar transformações de curto prazo, típicas de certas políticas públicas? Seria adequado para a definição ou avaliação de qualquer (ou de alguma) política?²

Tais questionamentos levaram várias instituições produtoras de informações, sobretudo as de âmbito estadual, a buscar o desenvolvimento de novos indicadores sintéticos, inspirados no IDH, mas considerando as necessidades e especificidades de seus respectivos Estados. Num contexto de grande interesse por indicadores municipais, a difusão de indicadores sintéticos, com tal cobertura geográfica, cresceu de forma exponencial e desarticulada. ${ }^{3}$ Também aqui a contribuição da Fundação Seade, com seu Índice Paulista de Responsabilidade Social - IPRS, foi relevante.

Assim, essas instituições passaram a ter a necessidade de se aparelhar técnica e cientificamente (inclusive com a aquisição e o domínio de pacotes estatísticos mais avançados e dispendiosos) para contribuir e participar do debate em torno dos indicadores sintéticos, assim como para atender à demanda de diferentes usuários, interessados nessa nova "família" de indicadores.

Além dos esforços dirigidos à elaboração de indicadores sintéticos, em especial referidos a municípios, vários outros avanços metodológicos ocorreram nos últimos anos. Entre eles destacam-se as estatísticas espaciais e o geoprocessamento. Também nesse caso, não foram desprezíveis os investimentos por parte das instituições produtoras de estatísticas em capacitação de pessoal, desenvolvimento e aquisição de informações passíveis de geoprocessamento, softwares, bases cartográficas, imagens de satélite e equipamentos. Note-se que esse tipo de informação passou a ter interesse crescente, seja pela já mencionada ênfase na focalização das políticas sociais
- em que a localização espacial das populações-alvo é particularmente importante -, seja pela introdução de novos temas na agenda da produção de informações, como meio ambiente e violência urbana, em que a delimitação precisa da área de ocorrência dos eventos que se deseja mensurar é relevante.

Houve, portanto, em simultâneo ao grande crescimento da demanda por informações estatísticas, o aumento da complexidade dessas informações, de sua abrangência temática e das formas de sua análise e apresentação. Recorrendo, porém, mais uma vez, a Senra, convém ter presente que "métodos e mais métodos são criados e usados, considerando todos os aspectos do processo de geração das estatísticas, lançando-se mão de novas e melhores tecnologias de comunicação, de observação, de apresentação, de processamento. Mas, em que pese a importância desses avanços, os principais 'instrumentos' são ainda as massas de seres humanos: para registrar, interpretar, classificar, perguntar" (Senra, 1999). Em outros termos, tal como nas demais atividades humanas, mas com maior ênfase na produção de estatísticas, a qualidade das informações é função direta da qualidade do pessoal envolvido em sua elaboração. Desse modo, ao se pensar sobre as possibilidades de avanço e de aprimoramento da produção de informações estatísticas este aspecto não deve ser menosprezado.

\section{INSTITUIÇÕES PRODUTORAS DE INFORMAÇÕES ESTATÍSTICAS}

Quanto às instituições produtoras de informações estatísticas, cabe destacar alguns dos problemas com que se defrontaram no período recente. Durante o período autoritário, a centralização das decisões era a regra. Portanto, a produção de estatísticas subordinava-se às necessidades do planejamento nacional, em especial no campo econômico, fazendo com que a Contabilidade Nacional e os Censos Demográficos e Econômicos constituíssem o cerne das estatísticas nacionais.

Em 1967, concebeu-se a Pesquisa Nacional por Amostra de Domicílios - PNAD (Fletcher; Ribeiro, s.d.), que buscava prover o Estado Nacional de informações necessárias ao planejamento socioeconômico. ${ }^{4}$ Do ponto de vista metodológico, conforme um estudo da época citado por Fletcher e Ribeiro (s.d.), o advento da PNAD significou a consagração "da técnica de amostragem como processo para obtenção de dados considerados essenciais para o desenvolvimento de estudos básicos para estabelecimento 
dos planos e programas que deverão acelerar o desenvolvimento econômico e social do país" (Oliveira, 1970).

A PNAD foi concebida, inicialmente, para prover informações demográficas e socioeconômicas para o conjunto do país. Ingerências oriundas de órgãos de planejamento regional (Sudam, Sudene, Sudeco e Sudesul), que demandavam dados da PNAD com detalhamento regional, fizeram-na ampliar sua abrangência geográfica (Fletcher e Ribeiro, s.d.), ${ }^{5}$ o que se refletiu no aumento de sua amostra: o plano amostral original, de 30 mil domicílios, ampliou-se, chegando a 110 mil, em 1982 e a 130 mil, em 2002.

Entre o final dos anos 60 e o início dos 80, uma série de novas pesquisas foram introduzidas pelo IBGE, como as pesquisas industriais, vários índices de preços e a Pesquisa Mensal de Emprego. Assim, esse período se caracterizou por importantes avanços técnicos e metodológicos e pela grande proliferação de estatísticas que, reafirmese, visavam muito mais atender aos interesses do planejamento nacional, do que dos demais entes federados e dos vários agentes econômicos e sociais. Mesmo assim, não se pode negar o excepcional desempenho do IBGE ao longo desses anos. Todavia, o sucesso alcançado no período e o próprio caráter centralizador do governo geraram certa auto-suficiência dos produtores de estatísticas (Senra, 1999; Guizzardi Filho; Conti, 2001), tornando-os impermeáveis às novas necessidades e às críticas, muitas delas oriundas do próprio governo, que não tardaram a surgir. Recorde-se que, já a partir do final dos anos 70, começa a se esboçar a crise que atingiu a economia e o Estado brasileiros, de que decorreram novas demandas por informações, capazes de explicar essa conjuntura. A incapacidade em atendê-las adequadamente, seja pela mencionada inflexibilidade, seja pelas próprias restrições orçamentárias, que se acentuaram no período, acabou minando a própria credibilidade da instituição.

Com a redemocratização do país, já mencionada, aprofundou-se o processo de descentralização e municipalização das ações governamentais. Ora, a multiplicação de centros de decisão governamental, em si mesma, gerou aumento das necessidades de informação, potencializada pelas novas oportunidades abertas pelas TICs. Desse modo, deixaram de ser suficientes as informações abrangentes, de cobertura nacional ou mesmo regional. Requerem-se, agora, além de todo o cardápio de estatísticas nacionais, informações específicas, freqüentes e com detalhamento municipal e, muitas vezes, intramunicipal.

As dificuldades, no entanto, não pararam aí. Ao final dos anos 80 , disseminam-se questionamentos sobre o pa- pel do Estado e da própria eficácia do planejamento. As dificuldades orçamentárias, associadas à descrença da própria capacidade do Estado em definir os rumos do desenvolvimento e mesmo de executar suas políticas, provocaram efeitos deletérios sobre as instituições produtoras de estatísticas, simbolizados pelo adiamento da coleta de informações do Censo Demográfico de 1990, que só foi a campo no ano subseqüente.

Não deixa de ser paradoxal a situação vivida naquele período: o aumento exponencial da demanda por informações e das novas possibilidades tecnológicas e metodológicas aplicáveis em sua produção encontra seus produtores oficiais numa situação de extrema fragilidade.

Apenas ao longo dos anos 90 a situação começa a se estabilizar, sobretudo no IBGE. Grandes esforços foram realizados para sua reorganização e modernização, em termos tecnológicos e metodológicos. A substituição dos censos econômicos por pesquisas amostrais - bem mais ágeis e menos custosas e passíveis de serem complementadas com "pesquisas-satélite" (mas com importantes limitações para seu detalhamento espacial) - simbolizam esses avanços, assim como a revisão metodológica da PNAD e, mais recentemente, da PME. Também atestam essa nova fase, entre outros avanços, o bem-sucedido Censo Demográfico de 2000, a introdução das contagens populacionais na metade do período intercensitário, a inclusão de novos temas na agenda de pesquisas do IBGE, como inovação tecnológica e meio ambiente, e as facilidades de acesso aos resultados de suas pesquisas, inclusive na forma de microdados.

Outros órgãos federais produtores de informações primárias ou de registros administrativos lograram obter progressos importantes, ampliando significativamente a oferta e o acesso a informações de qualidade sobre diferentes temas de interesse público, como o mercado de trabalho formal, o ensino e os serviços de saúde.

Como resultado das marchas e contramarchas que marcaram os últimos 20 anos, sobretudo no campo da produção de estatísticas, várias outras instituições públicas federais, estaduais, municipais e mesmo organizações privadas, não-governamentais e acadêmicas passaram a produzir informações estatísticas. ${ }^{6} \mathrm{O}$ grande desafio do momento é a constituição de uma coordenação nacional dos entes produtores de informações, papel que o IBGE deveria assumir mais agressivamente. Em certa medida, os primeiros passos nessa direção já foram dados, como a instituição da Comissão Nacional de Classificações Concla e os esforços coordenados pelo IBGE, com a par- 
ticipação das instituições estaduais, para a produção das contas regionais. Mesmo assim, falta muito a se avançar nesse campo, decisivo para que o país construa um verdadeiro Sistema Nacional de Estatística.

\section{FUNDAÇÃO SEADE}

Em meio a esse período turbulento, há 25 anos, nasce a Fundação Seade, herdeira de outros órgãos da administração pública estadual que remontam ao final do século XIX. ${ }^{7}$ Já em seu primeiro ano de existência, passa por sérios problemas orçamentários, que a obrigam a reduzir seu quadro de pessoal e a abrangência de sua atuação. Até meados dos anos 80, dedica-se basicamente aos estudos demográficos e à coleta e organização de dados secundários e de registros administrativos.

A partir daí, realizou um grande esforço de revisão das metodologias de pesquisas sobre força de trabalho - logo após o período crítico por que passou a economia brasileira e paulista, com graves reflexos sobre o mercado de trabalho na Região Metropolitana de São Paulo - e, em conjunto com o Dieese, desenvolveu e levou a campo, a partir de 1984, a Pesquisa de Emprego e Desemprego PED. Note-se que o governo de então, preocupado com a situação social do Estado e com as fortes manifestações sociais decorrentes da deterioração do mercado de trabalho metropolitano, necessitava de informações sobre o tema, adequadas à realidade regional, e determinou à Fundação Seade que as desenvolvesse.

A realização dessa pesquisa permitiu à Fundação Seade capacitar-se, seja no campo teórico-metodológico, seja no da realização de levantamentos primários, abrindo assim uma perspectiva promissora e que foi crescentemente trilhada pela instituição. No final da década de 80, uma nova pesquisa foi desenvolvida pela Fundação - a já mencionada PCV, cuja primeira tomada ocorreu em 1990 - que, ao adotar uma abordagem inovadora para a mensuração e caracterização da pobreza, que transcendia a perspectiva simples do cálculo da linha de pobreza, demonstrou sua capacidade de intervir, com competência, na fronteira do conhecimento social da época.

Houve, assim, um primeiro ciclo de atuação da Fundação Seade, centrada na produção de estudos demográficos, logo enriquecidos com novos aportes de estatísticas sociais. Note-se que se está falando de um período em que o chamado resgate da dívida social estava no centro das discussões e das propostas políticas dos primeiros governadores eleitos pelo voto popular. As necessidades de novas informações estatísticas, sobretudo sociais e com corte regional, que não vinham sendo supridas pelo IBGE pelas razões expostas anteriormente, passaram a ser produzidas, no caso do Estado de São Paulo, pela Fundação Seade.

No início da década de 90, após importantes investimentos em recursos humanos e tecnológicos, a Fundação Seade preparou-se para novos desafios. Com a substituição dos Censos Econômicos do IBGE pelas pesquisas amostrais, as possibilidades de detalhamento espacial das informações econômicas ficaram bastante limitadas. Além disso, novas questões referentes à reestruturação produtiva e à introdução de inovações tecnológicas, até então apenas conhecidas por meio de estudos de casos mas cujos efeitos sobre o mercado de trabalho já vinham sendo captados pela PED, necessitavam ser melhor estudadas. Nesse contexto, veio à luz a Pesquisa da Atividade Econômica Paulista - Paep, que não só supriu o Estado de informações detalhadas sobre a atividade econômica, como permitiu mensurar a extensão e as características da reestruturação tecnológica e gerencial por que passavam as empresas paulistas.

Outra frente de expansão das atividades da Fundação foi a coleta e produção de informações sobre as administrações municipais. Na esteira da expansão da demanda por informações municipais decorrente do processo de municipalização das ações de governo, a Fundação Seade, que já coletava informações sobre as administrações municipais, optou por reestruturar suas atividades nesse campo, constituindo, desde 1992, a Pesquisa Municipal Unificada - PMU, atualmente com periodicidade bianual. Esta pesquisa coleta informações sobre as estruturas administrativas e de recursos humanos e financeiros das prefeituras paulistas, bem como sobre a gestão municipal das políticas e dos serviços públicos, abarcando quase 800 variáveis em seu questionário.

Diversos levantamentos primários têm sido realizados pela Fundação Seade, em geral com ênfase em temas ou regiões específicas, atendendo a solicitações de seus inúmeros parceiros e clientes. Alguns se resumem ao cadastramento de famílias a serem beneficiadas por determinado programa social e outros se referem a pesquisas propriamente ditas. Como é sabido, a coleta primária de informações, além de dispendiosa, possui ritmo próprio que decorre das diversas fases que necessariamente tem de percorrer (planejamento, coleta e tratamento dos dados), nem sempre adequado às necessidades dos usuários. Assim, a utilização de registros administrativos tem-se 
mostrado uma opção cada vez mais interessante para os usuários, tanto mais pela melhoria da qualidade que tais informações experimentaram nos últimos anos.

A produção das estatísticas vitais, por exemplo, um dos temas em que a Fundação Seade goza de grande prestígio, faz-se por meio das informações do registro civil. Para tanto, são coletados mensalmente os dados sobre nascimentos, casamentos e óbitos nos 849 cartórios de registro civil do Estado, compondo um banco de dados que incorpora, a cada ano, cerca de 1,2 milhão de novos registros. Um subproduto desse levantamento foi a informatização dos cartórios, que teve decisiva participação da Fundação Seade. Não por acaso o Estado de São Paulo é uma das poucas unidades da federação que possui informações atualizadas e com o máximo detalhamento espacial de todas as informações demográficas relevantes, como as taxas de mortalidade por causa, sexo e idade, de fecundidade, natalidade e nupcialidade.

Vários outros registros administrativos são coletados pela Fundação Seade (Quadro 1). Alguns são bem organizados e documentados pelas instituições produtoras, mas muitos requerem um minucioso trabalho de análise, tratamento e organização das informações em banco de dados consistentes e dotados de toda a documentação necessária a seu manuseio.

Foi a disponibilidade de tais informações que permitiu à Fundação atender à solicitação da Assembléia Legislativa do Estado de São Paulo para produzir um indicador que permitisse o acompanhamento da situação socioeconômica de cada um dos 645 municípios paulistas, o Índice Paulista de Responsabilidade Social - IPRS. Além de um desenho metodológico inovador, com o concurso de sofisticadas técnicas estatísticas, sua construção se baseou em informações do registro civil, das Secretarias da Fazenda e da Educação do Estado de São Paulo, das empresas concessionárias de energia elétrica, do Ministério do Trabalho e Emprego, além dos microdados do Censo Demográfico. Sua elaboração dependeu não só do conhecimento de metodologias e técnicas estatísticas, mas de todo um trabalho de coleta e organização de bases de dados, com origens e características tão distintas, que exige habilidades específicas para seu manuseio. A reunião dessas competências e desse acervo de informações é, sem dúvida, o principal ativo da Fundação Seade.

É bom lembrar que todos esses esforços se concretizaram em meio a uma importante crise das finanças estaduais. Assim, ao lado de suas atividades de produção de informações para uso geral, que se aperfeiçoaram e tive- ram seu escopo temático ampliado, como se procurou demonstrar, a Fundação Seade passou também a realizar uma série de pesquisas, estudos, diagnósticos, avaliações e cadastros para diferentes instituições, em geral públicas, complementando, desse modo, suas necessidades de financiamento. Se isso lhe permitiu capacitar-se para novas funções e preservar um corpo técnico qualificado, também redirecionou capacidades e recursos para outras áreas que não a estrita produção e análise de informações estatísticas. Uma das áreas que mais se ressentiu da carência de investimentos foi a de armazenamento e disponibilização das informações.

\section{QUADRO 1}

Bases de Dados Disponíveis da Fundação Seade Classificadas por Tema

\begin{tabular}{lc}
\hline Tema & №s Absolutos \\
\hline Total & 93 \\
Administração Municipal & 1 \\
Administração Pública & 1 \\
Agropecuária & 2 \\
Comércio & 1 \\
Condições de Vida & 1 \\
Demografia & 6 \\
Demografia (Georreferenciada) & 1 \\
Desenvolvimento Humano & 1 \\
Educação & 20 \\
Educação (Georreferenciada) & 2 \\
Eleições & 1 \\
Estatísticas Municipais & 2 \\
Estatísticas Vitais & 8 \\
Finanças Públicas Estaduais & 6 \\
Finanças Públicas Municipais & 11 \\
Indústria & 1 \\
Informações Socioeconômicas e Demográficas & 6 \\
Infra-estrutura (Georreferenciada) & 1 \\
Mapas de Setor Censitário & 2 \\
Meio Ambiente (Georreferenciada) & 1 \\
Mercado de Trabalho e Emprego & 3 \\
Orçamento Familiar & 1 \\
Saúde & 12 \\
Transporte & 1 \\
Transporte (Georreferenciada) & 1 \\
\hline Font: Funa Sad & \\
\hline
\end{tabular}

Fonte: Fundação Seade.

\section{ARMAZENAMENTO E DISPONIBILIZAÇÃO DE INFORMAÇÕES}

A Fundação Seade realizou esforços significativos para atualizar-se técnica e metodologicamente, tem prestado serviços relevantes à sociedade paulista e brasileira, assim como para a administração pública nas três esferas de 
governo. Reuniu grande acervo de informações estatísticas, mas a forma de seu armazenamento e disponibilização, tanto para seu próprio corpo técnico como para usuários externos, ainda requer inúmeros esforços para ser aperfeiçoada.

O Quadro 1 busca sintetizar esse acervo, revelando para cada um dos múltiplos temas o número de bancos de dados disponíveis. Evidentemente, esse quadro dá apenas uma visão parcial do acervo, uma vez que os bancos de dados ali mencionados possuem coberturas e detalhamentos geográficos e temporais distintos, alguns são mais especializados outros mais genéricos, ainda que classificados no mesmo tema, e suas dimensões são muito distintas. Embora estejam em meio eletrônico, possuem diferentes formatos e alguns seriam melhor descritos como arquivos eletrônicos e, talvez, nem possam ser chamados, estritamente, de banco de dados. Ademais, não estão considerados nesse quadro os arquivos com informações mais antigas, armazenadas em papel ou microfichas, que ainda esperam uma oportunidade para serem digitalizadas. É fácil perceber os esforços necessários para sua simples atualização, uma vez que, além dos produzidos pela própria Fundação, foram incluídos os originários das mais distintas instituições.

Atualmente, esses bancos são fragmentados e gerenciados por técnicos alocados nas diferentes áreas da Fundação Seade, de modo que, vistos em conjunto, assemelham-se muito mais a um sistema de arquivos tradicional do que a um banco de dados institucional e integrado. Ainda que não se pretenda fundir todos esses conjuntos de informações num único banco, muito pode ser feito para integrá-los e reduzir várias das desvantagens características do atual sistema. Entre suas desvantagens, podem-se mencionar:

- a falta de flexibilidade, pois o acesso a diferentes bancos de dados implica a mobilização de distintas áreas da instituição, com suas próprias prioridades de trabalho. Assim, a produção de relatórios específicos nem sempre pode ser realizada rapidamente, sem prejudicar outras atividades da área responsável pelo gerenciamento do banco que se deseja consultar. Torna-se ainda mais difícil e demorada a produção de relatórios que envolvam informações contidas em mais de um banco de dados;

- a redundância dos dados, entendida como a possibilidade de a mesma informação estar contida em mais de um banco de dados. Além de ocupar espaços de armazenamento desnecessários e envolver maior trabalho de atualização, ainda se corre o risco de, caso cada um deles ado- tar, por exemplo, critérios próprios de arredondamento de valores fracionários, atribuir a um mesmo dado valores diferentes;

- a falta de padronização das nomenclaturas e das classificações é outro problema associado a este sistema de armazenamento de dados. A adoção de códigos de municípios diferentes em duas bases de dados, por exemplo, dificulta sua utilização conjunta, que pode ser ainda agravada se os nomes dos municípios também adotarem grafias distintas. Da mesma forma, a adoção de sistemas de classificação diferentes (de setor de atividade econômica, por exemplo) torna seu uso mais complexo e tende a levar à existência de dados com o mesmo nome associados a fenômenos diferentes ou, ao contrário, que um mesmo fenômeno seja denominado de forma diferente em bancos de dados distintos;

- as dificuldades de manutenção num sistema desse tipo são evidentes. Várias pessoas, pertencentes a diferentes áreas da instituição, com prioridades e ritmos de trabalho próprios, são mobilizadas para tanto. Assim, dificilmente se dispõe de uma posição atualizada da situação de cada uma das bases da Fundação;

- a multiplicidade de softwares é mais uma das desvantagens que este sistema apresenta, pois como cada banco constituiu-se independentemente, seus dados estão armazenados em softwares diferentes. Evidentemente, esta característica reduz a flexibilidade do sistema e eleva seus custos de manutenção e o tempo das consultas;

- por fim, um sistema fragmentado como esse dificulta a elaboração da documentação necessária à definição e descrição da base de dados (metadados) e, portanto, o acesso direto dos usuários aos bancos de dados.

Um sistema com essas características negativas acaba por reduzir a própria capacidade de atuação do conjunto da Fundação, impedindo-a de ampliar sua produtividade e reduzir seus custos e dificultando a elaboração de respostas rápidas a consultas ad hoc e a perguntas imprevistas, freqüentemente dirigidas a instituições com as características da Fundação Seade por seus múltiplos usuários.

Sua superação, no entanto, requer tempo, recursos humanos e investimentos, todos eles escassos na atual conjuntura econômica do Estado e do país. Mesmo assim, os primeiros passos nessa direção já vem sendo dados.

Entre as primeiras providências para reduzir a fragmentação desse sistema está o armazenamento conjunto dos dados em um único servidor, a fim de facilitar o controle 
de sua atualização e manutenção e reduzir a dependência dos usuários em relação a seus atuais gerenciadores. Para tanto, será necessário padronizar nomenclaturas e classificações e aperfeiçoar os metadados que, além de reduzir as redundâncias e eventuais inconsistências dos dados, tornará o sistema mais flexível.

Os passos subseqüentes, que induzam, na medida do possível, a efetiva integração desse sistema, ainda dependem de estudos que conduzam às decisões mais acertadas, até para a definição de um sistema de gerenciamento que facilite e controle, o acesso e o uso da base da Fundação, garantindo a flexibilidade, a integridade e a segurança de seus dados.

Nos 25 anos de existência da Fundação Seade, muito se avançou, sobretudo no que diz respeito ao volume e à qualidade de seus resultados. Seu perfil se modificou, não podendo mais ser vista como uma instituição dedicada exclusivamente à produção de informações estatísticas, ainda que tenha sido exatamente essa característica que lhe tenha permitido trilhar outros caminhos.

Assim, sua gestão ficou mais complexa e as necessidades de aperfeiçoamento de seu corpo técnico e de seus recursos tecnológicos se ampliaram. Num contexto de restrições fiscais, a Fundação Seade vem avançando, enfrentando desafios e provendo a sociedade com informações fundamentais para o seu desenvolvimento.

\section{NOTAS}

O autor agradece às sugestões de Vivaldo L. Conti para a elaboração deste artigo.

1. Este estudo obteve certa repercussão internacional, chegando a ser publicado, em 1994, pelo Internacional Institute for Labour Studies, em Genebra (Fundação Seade, 1994).

2. Para maiores detalhes desse debate, ver Seade (2001) e Jannuzzi (2001).

3. Um rápido e não exaustivo levantamento realizado pela Fundação Seade nas instituições estaduais de pesquisa, estatística e planejamento sobre a elaboração de indicadores municipais desse tipo, identificou sua existência nos Estados do Rio Grande do Sul, Rio de Janeiro, Minas Gerais, Espírito Santo, Bahia, Ceará e Goiás, além de São Paulo.

4. Senra (1999) considera que o sucesso do planejamento econômico nacional, constatado no pós-guerra, levou, posteriormente, sua extensão para o campo social, implicando novas necessidades de informações estatísticas. Já nos anos 60 , era reconhecido o sucesso das experiências norte-americana e canadense em pesquisas contínuas de população, inspiradoras da PNAD, proporcionando informações para o planejamento socioeconômico (Fletcher e Ribeiro, s.d.).

5. Note-se que esse autores só destacam as ingerências de órgãos federais de planejamento regional, não fazendo menção a qualquer iniciativa dos governos estaduais para o maior detalhamento espacial da PNAD, o que atesta o caráter centralizado do planejamento e das ações públicas no período.
6. A explosão da produção de índices de preço pelas mais diversas instituições, sobretudo ao longo da década de 80 , é um bom exemplo desse movimento.

7. Essa breve reconstituição da história da Fundação Seade se baseia no trabalho de Guizzardi Filho e Conti (2001).

\section{REFERÊNCIAS BIBLIOGRÁFICAS}

ABRUCIO, F.L.; SOARES, M.F. Redes federativas no Brasil: cooperação intermunicipal no Grande ABC. São Paulo: Fundação Konrad Adenauer, 2001 (Série Pesquisas, n. 24).

ALBERTS, D.S.; PAPP, D.S.; KEMP III, W.T. The technologies of the information revolution. In: ALBERTS, D.S.; PAPP, D.S. (Org.). The information age: an anthology on its impact and consequences. Washington: National Defense University, 2002. Disponível em: $<$ http://www.ndu.edu/books $>$. Acesso em: 6 out. 2003.

CONTI, V.L. Informações socioeconômicas sobre o Estado de São Paulo. Comunicação e Educação, São Paulo, ECA-USP, n.21, p.107-112, maio/ago. 2001.

ERIKSON, R. Descripciones de la desigualdad: el enfoque sueco de la investigación sobre el bienestar. In: NUSSBAUM, M.; SEN, A. La calidad de vida. México: The United Nations University e Fondo de Cultura Económica, 1996.

FLETCHER, P.R.; RIBEIRO, S.C. A educação na estatística nacional. In: SAWYER, D. (Org.). PNADs em foco: anos 80. Belo Horizonte: Abep, [s.d.].

FUNDAÇÃO SEADE. Índice Paulista de Responsabilidade Social. São Paulo, 2001. Mimeografado.

. Survey of living conditions in the metropolitan area of São Paulo. Genebra: ILO/ILLS, 1994 (Research Series, n. 101).

Pesquisa de condições de vida: uma abordagem multissetorial. São Paulo, 1992.

GUIZZARDI FILHO, O.; CONTI, V.L. Produção e disseminação de informações socioeconômicas. Transinformação. Campinas: Programa de Pós-Graduação em Biblioteconomia - PUC-Campinas, v.13, n.2, p. 43-54, jul./dez. 2001.

JANNUZZI, P.M. Indicadores sociais no Brasil: conceitos, fontes de dados e aplicações. Campinas: Alínea, 2001.

KRELL, A.J. O municipio no Brasil e na Alemanha. São Paulo: Oficina Municipal, 2003.

OLIVEIRA, R.R. A utilização dos dados das pesquisas por amostra domiciliar. Revista Brasileira de Estatísticas, Rio de Janeiro, IBGE, v.31, n.122, 1970.

ORGANIZAÇÃO DAS NAÇÕES UNIDAS (ONU). International Definition and Measurements of Standards and Levels of Living. New York: United Nations Publications, 1954.

PROGRAMA DAS NAÇÕES UNIDAS PARA O DESENVOLVIMENTO (PNUD). Relatório do Desenvolvimento Humano no Brasil. Brasília: PNUD, 1996.

SENRA, N.C. Informação estatística: política, regulação, coordenação. Ciência da Informação, Brasília, IBICT, v.28, n.2, 1999.

Sinésio Pires Ferreira: Economista, Diretor Adjunto de Análise Socioeconômica da Fundação Seade (sinesio@seade.gov.br). 